\title{
INDENTATION SHAPE PARAMETERS AS INDICATORS OF SPOT WELD QUALITY
}

\author{
D. Bračun, I. Polajnar, J. Diaci \\ University of Ljubljana, Faculty of Mechanical Engineering, \\ Aškerčeva 6, 1000 Ljubljana, Slovenia, E-mail: janez.diaci@fs.uni-lj.si
}

\begin{abstract}
The contribution presents a laser-based method for three-dimensional (3D) measurements of the shape of electrode indentation. The method is based on illumination of the indentation with structured light and detection of the image of the illuminated indentation by means of a digital camera. Image processing algorithms are employed to determine the $3 D$ shape of the indentation. A batch of welds obtained form an automotive production process has been measured and analyzed for characteristic geometrical indentation parameters such as diameter, depth, presence of cracks and splash etc. The potential of indentation shape parameters to serve as indicators of spot quality is discussed.
\end{abstract}

Keywords: Laser profilometry, Laser triangulation, Spot-weld inspection

\section{Introduction}

Spot-weld quality includes several parameters (strength, external appearance, corrosion resistance...), which may have different relative importance as dictated by the circumstances of a particular industrial welding application. The ability to assess spot-weld quality as early and as fast as possible appears to the very important in current industrial production. Intensive research in the field of NDT is currently focused on the search for new methods, which would allow quality inspection of a spot-weld at the very moment when it is produced ("real-time" or "hot" weld inspection). Ideally, a new NDT method should be capable of inspecting $100 \%$ of the production output (in-line testing). Several NDT methods have been applied to assess and monitor spot-weld quality (visual inspection, ultrasonic, acoustic emission, penetrant, radiographic) [1-5]. These methods are time-consuming and not reliable enough to be acceptable for application in mass production where RSW is the most used joining technology. There is therefore a constant need for new approaches in research and development of NDT quality control in RSW.

Our recent research in this area has been concentrated on development of optical methods for spot-weld quality assessment [8-11]. We have developed a method, based on laser profilometry, which allows on-line measurement of three-dimensional (3D) shape of electrode indentation [1013]. The 3D indentation shape, acquired by this method, consists of multitude (several thousands) of measurement points. Our current research is focused on development of algorithms, which would allow determination of quality parameters from the measured 3D indentation shape. We have shown, for example, that it is possible to estimate the condition of 
the electrode tip from geometry of weld indentation, which opens the way for on-line monitoring of electrode wear during RSW [10]. We have also applied the method to measure electrode contact area [11]. The prerequisite for successful implementation of the method for automated on-line spot weld inspection and quality control is development of fast and reliable algorithms which would allow extraction of characteristic geometric indentation features (diameter, depth, volume...), identification of surface defects (cracks, pores, expulsion splash...), determination of electrode positioning errors, and local and/or global distortion of the weld-piece...

In this contribution we present the set-up that we are developing with the aim to increase the measurement precision of optical indentation measurement. We describe the algorithms for extraction of characteristic indentation features (diameter, depth, volume...) and discuss the results of 3D measurements of surface defects.

\section{Experiment}

The method we use for optical indentation measurement is based on the optical triangulation principle [15-17]. The weld-piece surface is illuminated by a laser source so that specific geometry details on the surface are enhanced. Surface illuminated in this manner is imaged by a camera that is placed at specific (triangulation) angle with respect to the direction of illumination. This arrangement enhances geometric characteristics of the measured object and enables determination of the 3D surface shape from the 2D acquired image.

In our previous work $[10,12,13]$ we used a triangulation set-up where the surface was illuminated with a laser beam formed into a fan of multitude (up to 100) sub-beams (light planes), which illuminated the weld-piece surface with a light pattern consisting of parallel bright and dark lines. This set-up allows very rapid measurements, because only one image is required to determine the shape of the illuminated surface. Measurement can thus be completed within a fraction of a second. Due to the high speed measurement precision is rather limited.
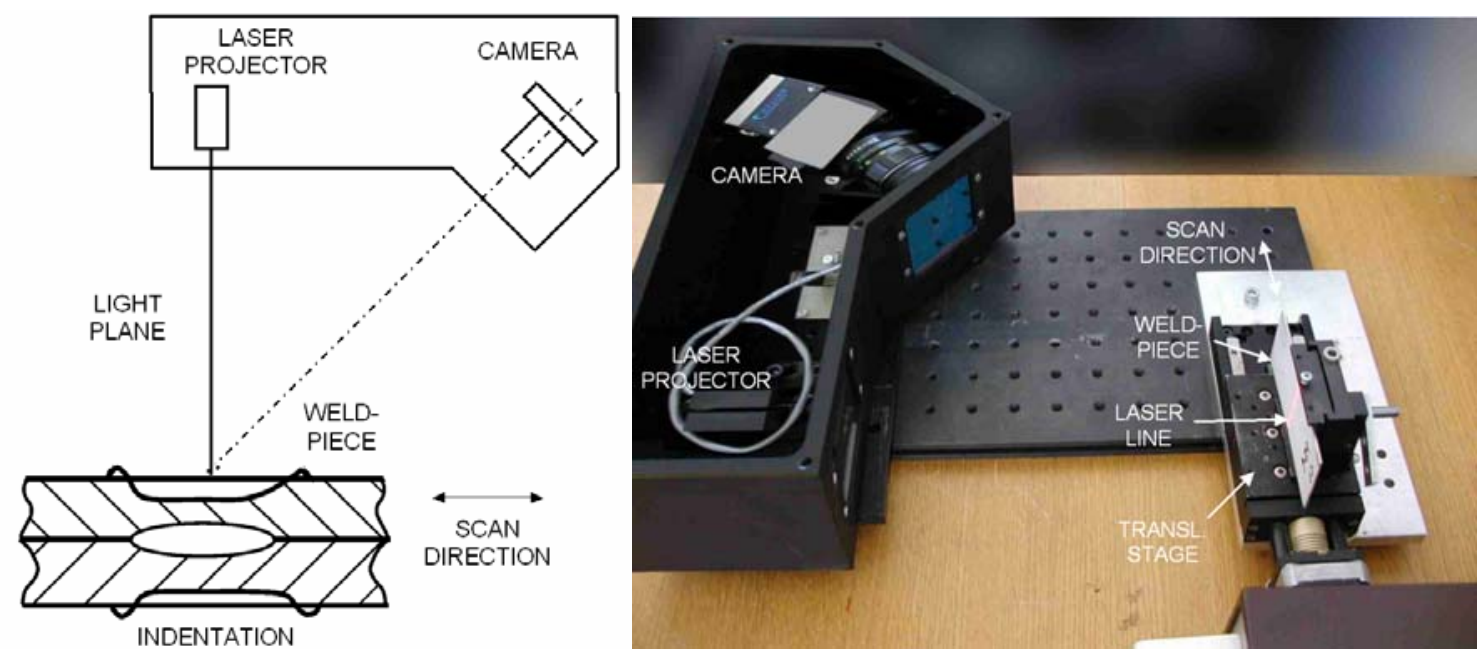

Fig. 1: Schematics (left) and photograph (right) of indentation measurement set-up.

In order to explore limits of precision that would allow reliable detection of weld surface defects we developed another set-up, which is inherently slower but offers better precision. In this set-up (Fig.1), a laser beam, formed into a single light plane, illuminates the weld-piece surface. Only one bright line is visible on the surface and is acquired by the camera. The result of one measurement is a profile representing a cross-section of the light plane and the illuminated surface. In order to measure the complete surface, the surface is scanned - the weld-piece is translated a direction perpendicular to the laser line using a precision translation stage driven by 
a micro-stepping motor. When the weld-piece settles in a new position, an image of the laserilluminated surface is acquired and a surface profile is determined. After that, the weld-piece is translated into a new position.

The smallest distance between profiles (scanning resolution) is $0.001 \mathrm{~mm}$ and depends on resolution of the translation stage. The surface acquisition process is rather slow - it takes about 1 second per profile. The major part of that time takes repositioning of the weld-piece. A typical scan length for indentation measurement is about $10 \mathrm{~mm}$. Scanning at resolution limit in this situation requires measurement of a total of 10.000 profiles and takes about $1.000 \mathrm{~s}$. We use such a high precision only for characterization of the smallest geometrical features (e.g. cracks). In a typical measurement we use the scanning resolution of $0.01 \mathrm{~mm}$.

Profile measurement resolution (distance between measured points along the laser line) depends on the size of the camera sensor element and on the optical magnification. In the reported set-up we use a monochrome 656 x 494 pixel, 1/2" CCD sensor, video camera with digital (IEEE-1394 alias "firewire") output. In this case, the achieved profile measurement resolution is $0.015 \mathrm{~mm}$.

At each measurement step, an image of the illuminated surface is acquired and processed by a PC to determine a surface profile. Denoting the scan direction as $x$ and the direction along the laser line (perpendicular to the scan direction) as $y$ we write a surface profile at a certain scan position $X_{i}$ as $Z\left(Y_{j}\right)$, where $Y_{j}$ is the position along the laser line direction. The complete measured surface is represented in the PC by a set of measured points written as $Z\left(X_{i}, Y_{j}\right)$, where $X_{i}$ and $Y_{j}$ are discrete variables. $Z\left(X_{i}, Y_{j}\right)$ represents elevation of a certain point on the weld-piece surface above the reference plane $x y$. The digital representation of the $3 \mathrm{D}$ weld-piece surface (commonly called "a cloud of points") $Z\left(X_{i}, Y_{j}\right)$ can be viewed from various viewpoints using a suitable rendering software. A typical result of indentation measurement using the described setup is shown in Fig. 2. A "nearly ideal" RSW spot was produced using a pair of new electrode tips of nearly spherical shape. The image on the left-hand side is a close-up photograph of the RSW spot, while the image on the right-hand side is the computer rendered 3D image from data obtained by optical indentation measurement.
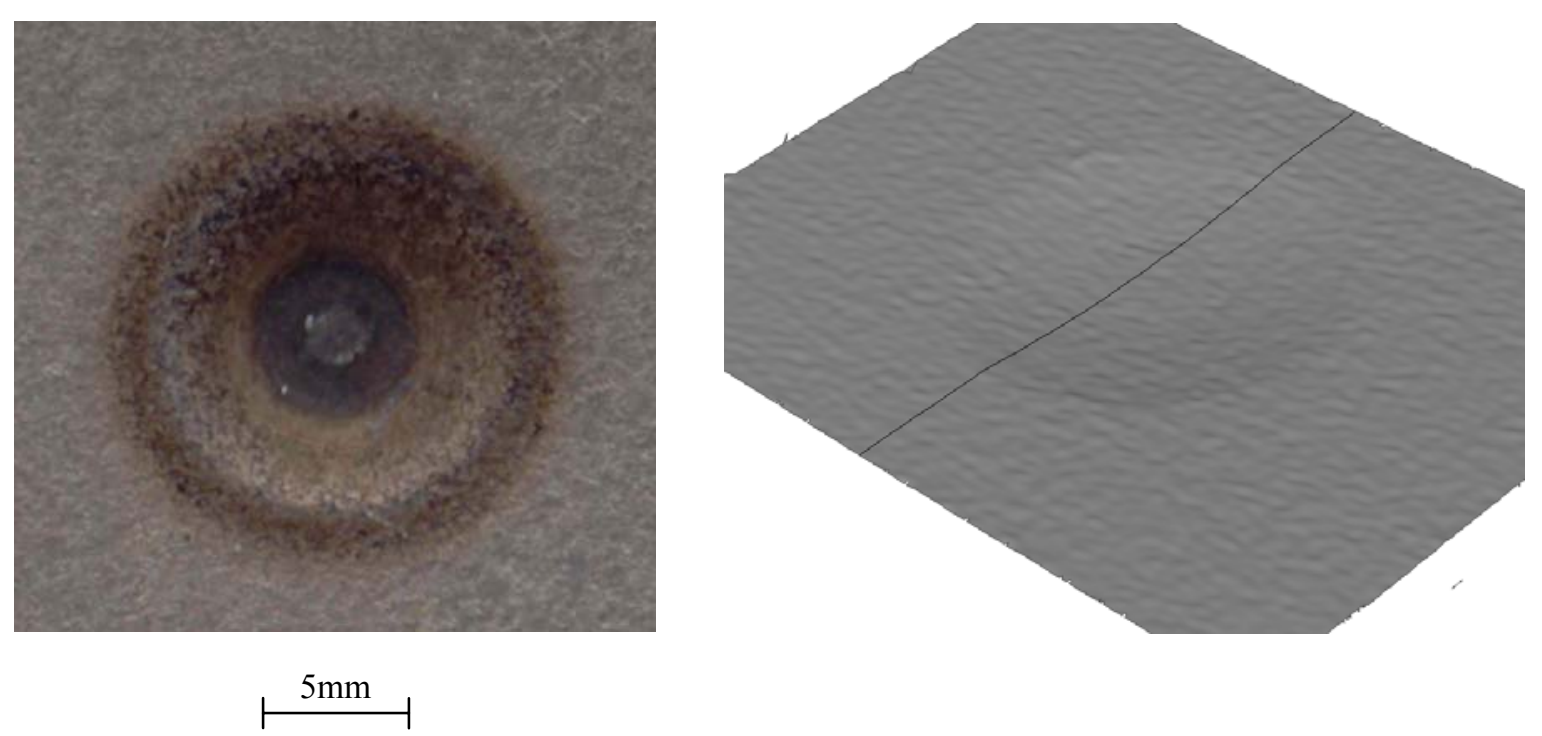

Fig. 2: RSW spot (“Ideal" indentation produced by a new nearly-spherical electrode tip). Photograph (left) and computer generated 3D images (right) from data obtained by optical indentation measurement.

In this particular case electrode indentation exhibits almost perfect circular symmetry. The 3D image clearly shows that the indentation is also very regular in the third dimension - exhibits the expected nearly spherical form. The two images in Fig. 2 demonstrate the benefits of the 3D 
shape detection methods in comparison with the $2 \mathrm{D}$ detection methods. The latter can give an estimation of the indentation diameter and elipticity, while the former give 3D weld-piece surface and allow determination of a much broader set of shape parameters. There are features on the photograph in Fig. 2 (e.g. beyond the outer edge of indentation) that are visible due to surface reflectivity alterations caused by welding and have no connection to the weld-piece surface shape. The described 3D measurement method is not sensitive to surface reflectivity alterations, because it depends on the measurement of laser line position not intensity and can therefore acquire the surface more accurately.

In a typical situation, the cloud of points $Z\left(X_{i}, Y_{j}\right)$ contains more than 6000 measured points per square millimetre and is thus quite unsuitable for direct quality assessment of a certain weld. Suitable algorithms for data reduction are therefore needed. Ideally, weld shape quality would be represented by a small number of scalar numerical parameters that would in final instance allow a precise and reliable classification of the produced welds into "acceptable" and "nonacceptable". Although some numerical parameters may be virtually self-evident, e.g. characteristic diameter, depth or volume of indentation, the question as to how to define weld quality from the viewpoint of surface measurement is central to the current research in this area.

\section{Indetation evaluation methodology}

Even the "self-evident" parameters need to be precisely defined in order to allow computer evaluation. There are no widely accepted definitions yet in this area, so we form ad-hoc definitions, which allow us to analyze the shape of a batch of welds. The following geometric properties of electrode indentation are examined (Fig. 3): the volume $V$ and the average depth $h$ of the electrode impression into the work-piece, and the average diameter $d$ of the indentation. The amount of material extruded over the surface level is not examined in this study.

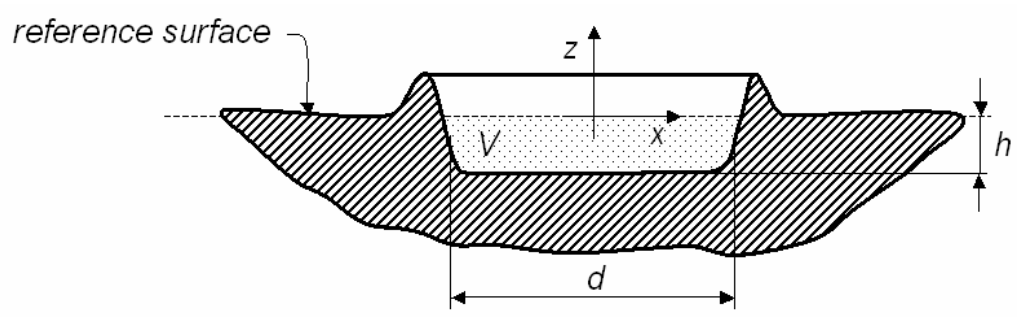

Fig. 3: Weld cross-section with indicated shape parameters.

In the first step to determine the mentioned shape parameters we establish a reference surface, which serves as a basis for the electrode impression measurements. The ideal reference surface this would be the measured pre-weld work-piece surface. In cases when it has not been measured, we use an approximation. We determine the reference plane by fitting a second-order polynomial to the 3D geometry of the surface $Z\left(X_{i}, Y_{j}\right)$. The error in the surface level caused by the indentation geometry (using the post-weld instead of the pre-weld surface) can be made negligible by choosing an optical magnification small enough so that the indentation diameter does not exceed approximately $1 / 3$ of the image size. The post-weld work-piece surface is translated to the vertical origin by subtracting the fitted surface level from it. By taking into account only those parts of the post-weld work-piece surface with a negative sign (the parts immersed into the work-piece) the post-weld surface can be treated as a set of immersed islands with the indentation surface representing the largest of them. The small islands are neglected, as they are mainly a consequence of noise.

The average indentation diameter $d$ is determined by fitting an ellipse to the set of boundary points $\left(X_{\text {bound }}, Y_{\text {bound }}\right)$ on the indentation surface 


$$
\frac{X_{\text {bound }}^{2}}{a^{2}}+\frac{Y_{\text {bound }}^{2}}{b^{2}}=1
$$

The ellipse half-axes $a$ and $b$ obtained by the fit are used to determine the average indentation diameter $d$

$$
d=a+b .
$$

They can also be used to evaluate elipticity: $a / b$.

The indentation volume $V$ and area $A$ are calculated by applying basic geometry equations in a discrete form:

$$
\begin{gathered}
V=\Delta X \Delta Y \sum_{i=1}^{768} \sum_{j=1}^{576} Z\left(X_{i}, Y_{j}\right) \\
A=\Delta X \Delta Y \sum_{i=1}^{768} \sum_{j=1}^{576} \delta\left(X_{i}, Y_{j}\right) \\
\delta\left(X_{i}, Y_{j}\right)=\left\{\begin{array}{cc}
1 & \text { if } Z\left(X_{i}, Y_{j}\right)<0 \wedge Z\left(X_{i+1}, Y_{j}\right)<0 \wedge Z\left(X_{i}, Y_{j+1}\right)<0 \wedge Z\left(X_{i+1}, Y_{j+1}\right)<0 \\
0 & \text { otherwise }
\end{array}\right.
\end{gathered}
$$

The indentation area $A$ is defined as the area of the planar shape enclosed by the curve representing the indentation edge. The average indentation depth $h$ is calculated by dividing the indentation volume $V$ by the indentation area $A$.

As an evidence that the above definitions have some relevance to the weld quality assessment we present in Fig. 4 the results of an experiment where we examined the gradual change of indentation volume $V$ as a consequence of electrode degradation. 600 welds were produced sequentially using the same pair of electrode tips and the same nominal welding parameters. Work-pieces of dimensions $40 \times 110 \mathrm{~mm}$ and thickness $2 \mathrm{~mm}$ were made from a hot-galvanised cold-rolled mild-steel sheet (St 37) and prepared in accordance with the DIN 5411 standard. The electrode was selected in accordance with the DIN 4458 standard: tip shape $d_{e}=7.5 \mathrm{~mm}, r_{1}=50$ $\mathrm{mm}$ and the material was $\mathrm{CuCr} 2.1291$ (DIN 44750).

The indentation-volume diagram (Fig. 4) reveals the dynamics of the wear process. During the first 60 welds the indentation volume decreases slightly. After that, during the next 180 welds, the indentation volume decreases quite rapidly at a nearly constant rate of about $7 \times 10^{-3}$ $\mathrm{mm}^{3} /$ weld (leftmost dashed line). After about 240 welds the volume-change rate undergoes a drastic change, dropping back to a nearly zero average value. Thereafter, the indentation volume varies around a nearly constant average value of about $0.9 \mathrm{~mm}^{3}$ (rightmost dashed line). The characteristic form of these diagrams allows us to define a characteristic number of welds (T) that can serve as a measure for quantifying the dynamics of electrode degradation. $T$ can be defined as the total number of successive welds made by a pair of electrode tips at which the indentation volume ceases to decrease.

The above definition of scalar shape parameters such as volume $V$, depth $h$, and diameter $d$ is very robust and will give meaningful results even in cases where indentation shape is highly irregular as, for example, in the described electrode wear experiment.

The scalar shape parameters can describe weld-shape quality only partially. They are defined to describe the global indentation properties and are thus not sensitive enough to certain local shape features, such as surface defects, which have a big influence on the weld-quality. In order to open ways for automated detection of surface defects using the laser profilometry method we examined typical examples of surface detects which occur in industrial practice. 


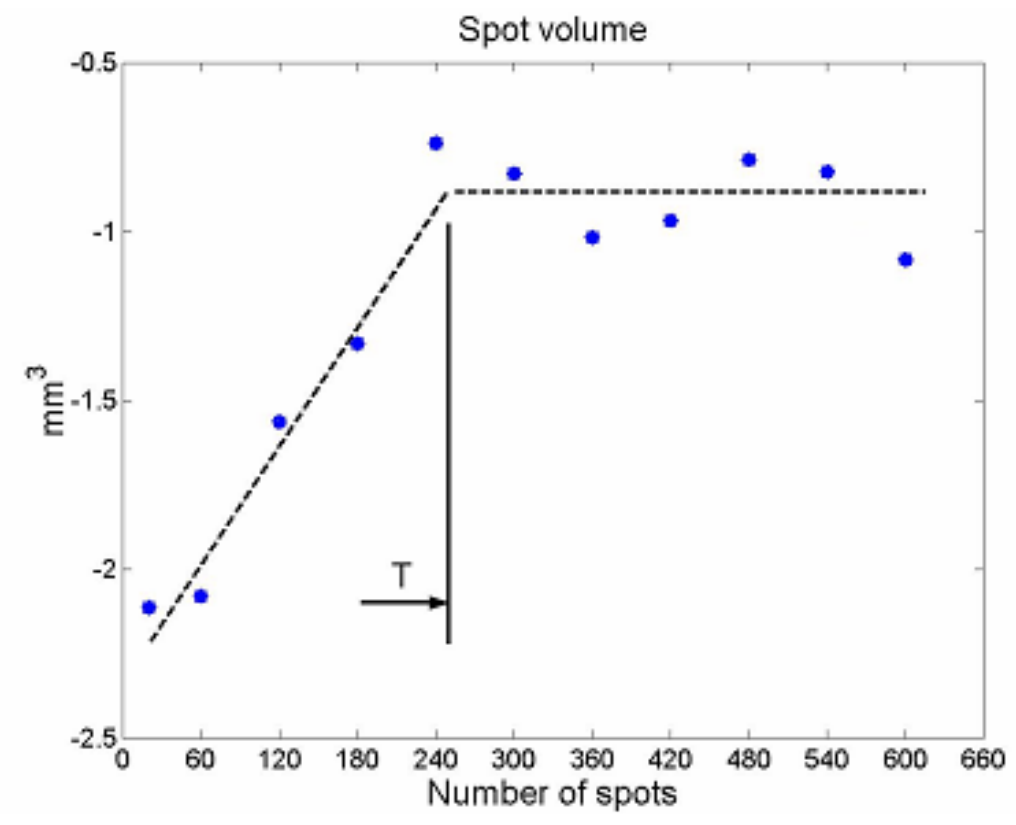

Fig. 4: Indentation volume as a function of number of consecutive weld spots produced by the same pair of electrode tips.

\section{Evaluation of weld surface defects}

A batch of spot-welds from the production of a car body has been measured using the above setup and analysed for characteristic surface features. Weld-pieces were made from zinc coated steel USt 10 (zinc coating $275 \mathrm{~g} / \mathrm{m}^{2}$ ) and had the thickness of $1.0 \mathrm{~mm}$. Figs. 5 to 8 show some typical examples - the images on the left-hand side are close-up photographs of the RSW spot, while the images on the right-hand side are the computer rendered 3D images (right) from data obtained by optical indentation measurement. The aim of the experiment was to examine the measurement precision required to detect common surface defects, which occur in industrial environment.
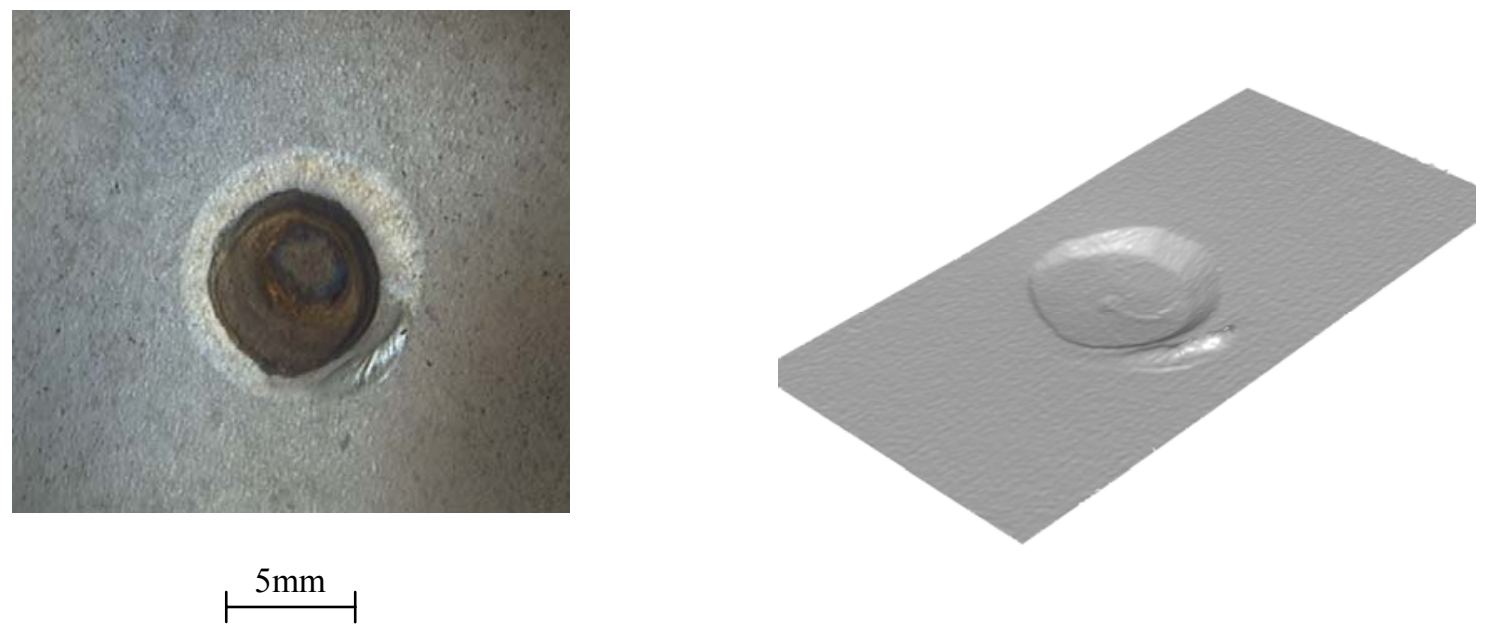

Fig. 5: RSW spot (asymmetric due to tip positioning error, surface defect on the indentation bottom and a ridge near the indentation edge). Photograph (left) and computer generated 3D images (right) from data obtained by optical indentation measurement. 
A very common fault in RSW is non-centric and non-coaxial positioning of electrode tips [6]. The result is non-symmetric electrode indentation and often non-acceptable spot-weld. As in Fig. 5 the method allows reliable detection of this type of faults.
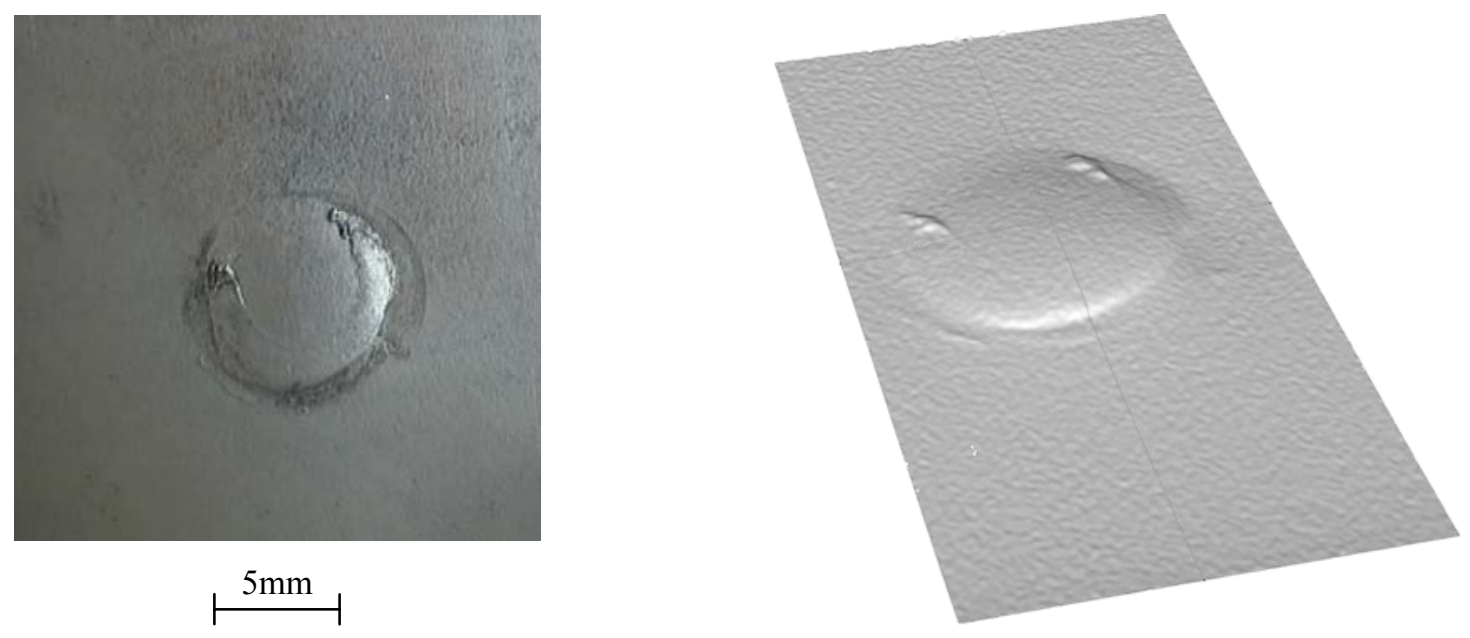

Fig. 6: Spot-weld produced by an electrode without tip. Photograph (left) and computer generated 3D images (right) from data obtained by optical indentation measurement.

The next common fault is that an electrode tip falls from the electrode holder due to e.g. loose tolerances or brazing of the electrode tip on the weld-piece surface... The consequence is a nonsymmetric weld nugget and unsuitable outer weld surface. Fig. 6 shows a sample weld produced without the upper electrode tip of the robot weld-gun. Evidently the method can detect this type of fault, which is not uncommon in welding of coated steels.
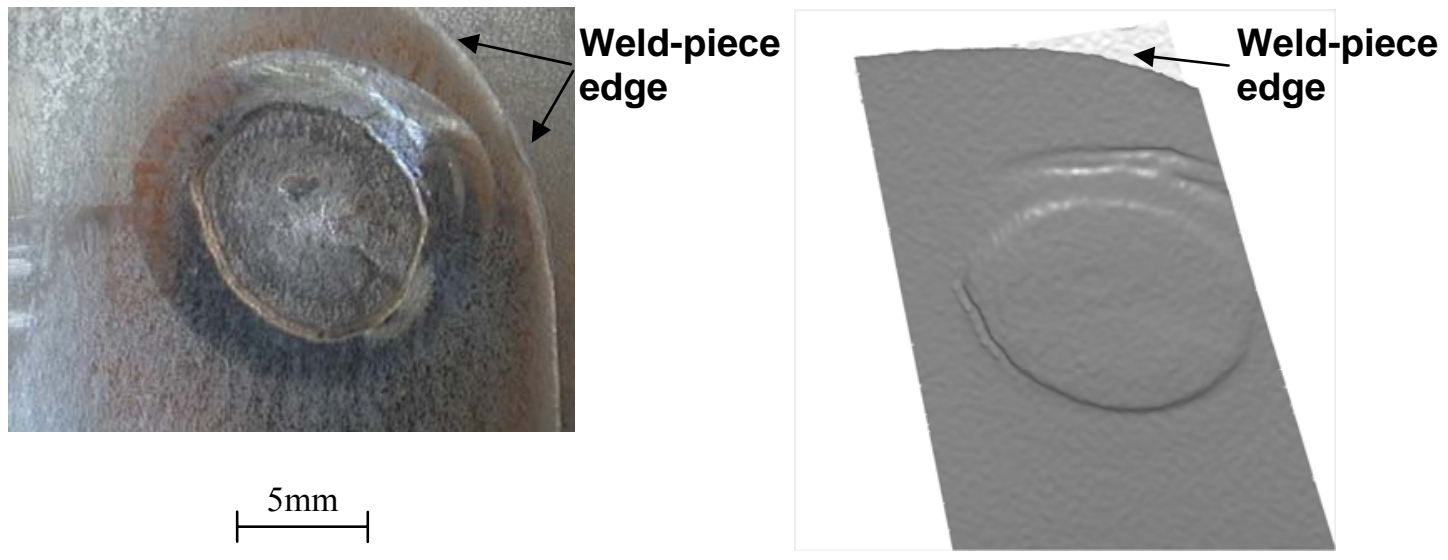

Fig. 7: RSW spot (indentation to shallow, spot position to close to weld-piece edge). Photograph (left) and computer generated 3D images (right) from data obtained by optical indentation measurement.

A quite common fault is related to improper positioning of the electrode tip relative to the weldpiece edge. In this case heat flow is non-symmetric relative to the electrode axis resulting in nonsymmetric nugget and often accompanied with splash. In Fig. 7 we show that this type of fault can easily be detected by the described method.

A consequence of unsuitable welding parameters is expulsion of melt, which can occur either between an electrode tip and weld-piece (external expulsion) or between the two weld-pieces (internal expulsion). Fig. 8 shows an example of external expulsion caused by zinc burning [7] 
from the weld-piece surface coating. The described method can reliably detect external expulsion. Internal expulsion can be detected if the spot-weld is positioned near weld-piece edge.
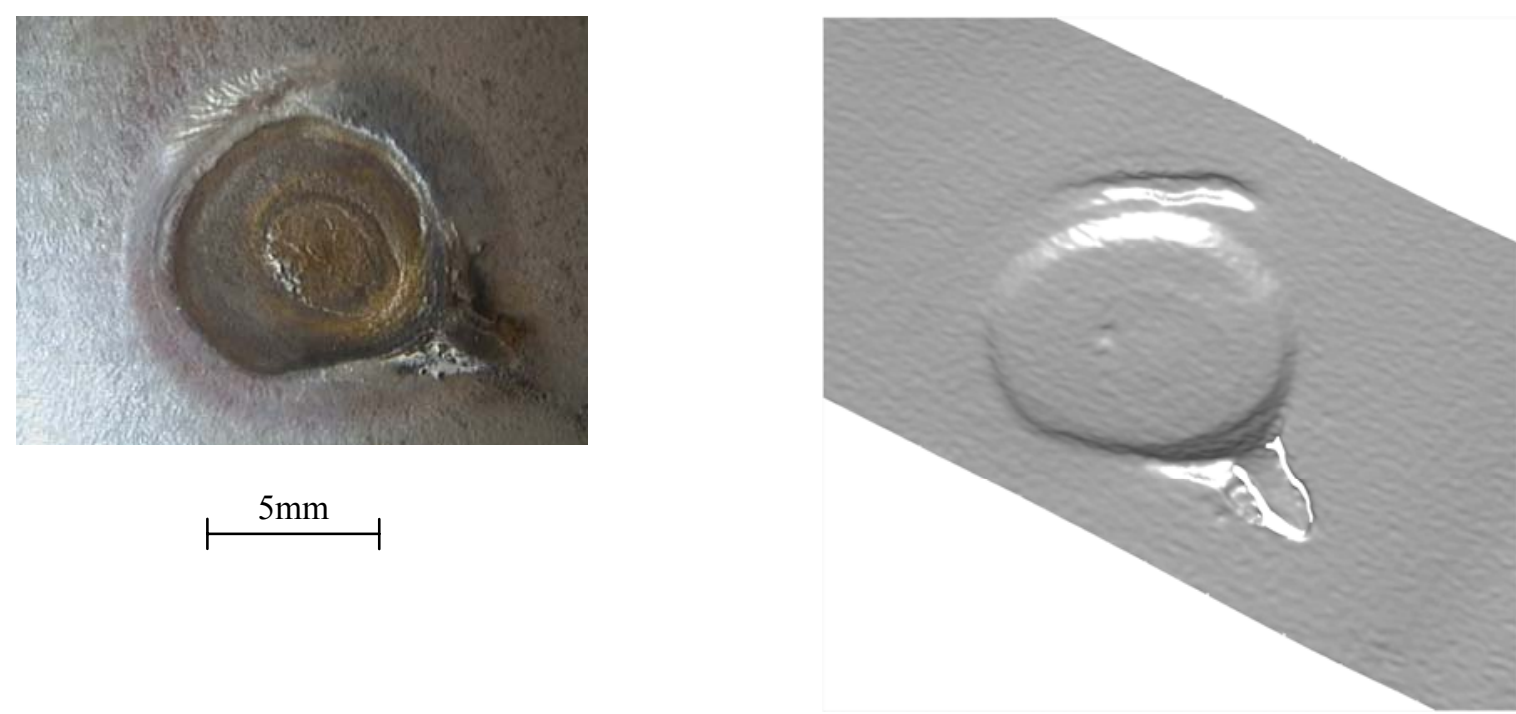

Fig. 8: RSW spot (asymmetric with surface deposit from expulsion between electrode tip and weld-piece surface caused by zinc burning). Photograph (left) and computer generated 3D images (right) from data obtained by optical indentation measurement.

\section{Conclusions}

The contribution presents a new method for RSW quality control based on 3D measurement of electrode indentation (the electrode impression into the work-piece) employing laser profilometry. The applicability of the method is demonstrated through indentation measurements of a batch of welds obtained form an automotive production process. We have defined scalar parameters (volume $V$, depth $h$, and diameter $d$ ), determined from the measured indentation shape data, in such a way that they provide meaningful results even in cases where indentation shape is highly irregular. We have examined the potential of the described method to detect local shape features, such as surface defects, which have a big influence on weld-quality. The results show that it possible to measure local shape features with the precision that would allow development of automated algorithms for surface defect detection. The method has the potential be applicable in industrial environment allowing "hot" weld quality inspection of each spot-weld produced.

\section{References}

[1] Satonaka S., Matsuyama K.: Review on Inspection Techniques for Spot Welds, IIW/IIS, Doc.:III-1134-99, Lisabon, 1999.

[2] Mansour, T.M.: Ultrasonic Inspection of Spot Welds in Thin-Gage Steel, Materials Evaluation, Vol. 46, No. 4, 1988, pp. 650-658.

[3] Eichhorn F., Hamm K.-J., Poell K., Schmitz G.: Development of a Microprocessor-based System to Determine Resistance-spot-weldability and Perform Electrode-life-tests Automatically, in Weld Quality - The Role of Computers, Pergamon Press, Oxford, 1988, pp. 113-121.

[4] Broomhead J.H., Dong P.H.: Resistance Spot Welding Quality Assurance, Welding \& Metal Fabrication, July 1990, pp. 309-314. 
[5] Chertov A., Maev R.: Determination Of Resistance Spot Weld Quality In Real Time Using Reflected Acoustic Waves, Proceedings of 16th World Conference on NDT, 2004, Montreal, Canada. http://www.ndt.net/article/wcndt2004/pdf/automotive/416_chertov.pdf

[6] Definitions Of Failure Types And Geometric Measurements For Weld Quality For Resistance Spot, Seam And Projection Weld, IIW/IIS Standardization activities document, IIW/IIS, Doc.:III-985-92, Madrid 1992.

[7] Lum I., Fukumoto S., Biro E., Boomer D.R., and Zhou Y., "Electrode Pitting in Resistance Spot Welding of Aluminium Alloy 5182", Metallurgical and Materials Transactions, Vol. 35A, 2004, pp. 217-226.

[8] Bračun D., Polajnar I., Možina J.: Identification of the shape of electrode's plague in resistance spot welding by laser profilometry, Proceedings of EUROJOIN 4, 4th European Conference on Welding, Joining and Cutting, Dubrovnik, 2001, pp. 285-289.

[9] Bračun D., Možina J., Polajnar I.: Laser Profilometry of Resistance Spot Welds, IIW/IIS, Doc.:III-1154-00, Florence, 2000.

[10] Bračun D., Diaci J., Polajnar I., Možina J.: Using Laser Profilometry to Monitor Electrode Wear During Resistance Spot Welding, Science and Technology of Welding and Joining, Vol.7, Oct.2002, No 5, Page 294-298.

[11] Polajnar I., Bračun D., Podržaj P., Diaci J.: 3D Measurement of electrode contact area in resistance spot welding of coated steel. Weld. world, 2004, Vol. 48, no. 11/12, 2004, pp. 26-30.

[12] Bračun D.: Meritev oblike teles na osnovi laserske triangulacije $=$ [Using laser triangulation to determine an object's shape]: $\mathrm{PhD}$ thesis, University of Ljubljana, Faculty of Mechanical Engineering, 2002.

[13] Jezeršek M.: Laserski sistem za tridimenzionalno merjenje hitro spreminjajoče se oblike teles $=$ [Laser system for three dimensional measurement of high speed object shape variation], PhD thesis, University of Ljubljana, Faculty of Mechanical Engineering, 2004.

[14] Jezeršek M., Gruden V., Možina J.: High-speed measurements of steel-plate deformation during laser surface processing. Opt. Express, 2004, Vol. 12, no. 20, pp. 4905-4911.

[15] Bradshaw G.: Non-contact surface geometry measurement techniques, The Dept. of History of Art, Trinity College, Dublin. (1999), http://citeseer.nj.nec.com/278983.html.

[16] Donges A. and Noll R.: Lasermeßtechnik, Grundlagen und Anwendungen, Hüthig, Heidelberg, 1993.

[17] Beraldin J.A., Blais F., Cournoyer L., Godin G. and Rioux M.: Active 3D Sensing, Modelli e metodi per lo studio e la conservazione dell'architettura storica, Scola Normale Superiore, Pisa 10 (2000), pp. 22-46, http://www.vit.iit.nrc.ca/VIT.html. 